Ĭğır Üniversitesi Fen Bilimleri Enstitüsü Dergisi, 11(2): 933-942, 2021

Journal of the Institute of Science and Technology, 11(2): 933-942, 2021

ISSN: 2146-0574, eISSN: $2536-4618$

Biology DOI: $10.21597 /$ jist.854685

Received: 05-01-2021

Research Article

Accepted: 27-01-2021

To Cite: Alaylar B, Karadayı M, 2021. Investigation of ACC-Deaminase and Indole Acetic Acid Producing Bacteria from Rhizospheric Soils in Ağrı Province. Journal of the Institute of Science and Technology, 11(2): 933-942.

\title{
Investigation of ACC-Deaminase and Indole Acetic Acid Producing Bacteria from Rhizospheric Soils in Ăgrı Province
}

\section{Burak ALAYLAR ${ }^{1 *}$, Mehmet KARADAYI ${ }^{2}$}

\begin{abstract}
Plant growth promoting rhizobacteria (PGPR) have critical role in promoting plant growth and health with various mechanisms. Production of indole acetic acid (IAA) and 1aminocyclopropane-1-carboxylate (ACC) deaminase activity are well-known plant growth promoting (PGP) properties. In the current study; A total of 48 morphologically distinct bacterial colonies were chosen during the isolation of bacteria from various rhizospheric wheat, maize and sainfoin soil samples from agricultural areas in Ağr1-Turkey. The bacteria were isolated from soil samples utilizing by culture-dependent techniques. Then, the strains were visualised for PGP activities such as production acetic acid IAA and ACC deaminase activity. The $16 \mathrm{~S}$ rRNA sequence similarity of potential PGPR rhizospheric strains demonstrated that strains belong to species Bacillus, Pseudomonas, Microbacterium, Pseudarthrobacter, Arthrobacter and Enterobacter. Totally, 11 of 48 isolates exhibited highly IAA producing and ACC deaminase activity. These results show that IAA producing and ACC deaminase activity of local potential PGPR strains isolated from soil rhizospheric which can appropriate for sustainable agricultural applications in Ağrı province.
\end{abstract}

Keywords: ACC deaminase activity, IAA production, PGPR, 16S rRNA

\footnotetext{
${ }^{1}$ Burak ALAYLAR (Orcid ID: 0000-0001-6737-3440), Agri Ibrahim Cecen University, Faculty of Arts and Sciences, Department of Molecular Biology and Genetics, Agri, Turkey

${ }^{2}$ Mehmet KARADAYI (Orcid ID: 0000-0002-2473-0409), Atatürk University, Faculty of Science, Department of Biology, Erzurum, Turkey

*Corresponding Author: Burak ALAYLAR, e-mail: balaylar@agri.edu.tr
} 


\section{INTRODUCTION}

Plant-microbe interactions have beneficial processes plenty of key roles in soil health, crop growth and productivity. Especially, soil microorganisms demonstrated positive effects on numerous agricultural applications. Among these soil microorganisms, plant growth promoting rhizobacteria (PGPR) was initially described as; soil bacteria that located into roots of plants and they have fruitful features when inoculation onto seed and improve to plant growth by Kloepper and Schroth (1978). Therefore, researchers have been attracted attention to microorganisms based fertilizers instead of chemical fertilizers because of their high cost and detrimental impacts on sustainable agricultural applications in past decades (Adesemoye et al., 2009; Beneduzi et al., 2012; Alaylar et al., 2019; Ferreira et al., 2019; Alaylar et al., 2020a). Furthermore; they have been identified and reported PGPR bacteria including; Alcaligens, Arthobacter, Azospirillum, Azotobacter, Bacillus, Burkholderia, Enterobacter, Klebsiella, Pseudomonas, Rhizobium and Serratia (Egamberdieava, 2015; Afzal et al., 2017; Ferreira et al., 2019). Besides, various beneficial mechanisms have shown of numerous type of favorable abilities for plant growth with various mechanisms. For example; atmospheric nitrogen $\left(\mathrm{N}_{2}\right)$ fixation, solubilization of phosphorus, improved to solubility of nutrients like synthesizing of siderophores, production of plant growth regulators such as cytokinins, ethylene, gibberellic acid, and indole acetic acid (IAA), and 1-aminocyclopropane-1-carboxylate (ACC) deaminase activity (Ahmad et al., 2008; Alaylar et al., 2020b).

According to the literature, one of the most frequently used mechanisms to explain the distinct effects of PGPR on plants is the production of phytohormones (Duca et al., 2014). Among these phytohormones; auxin is one of the important molecules that play a vital role in plants by regulating many processes in plants directly or indirectly (Bal et al., 2012; Junior et al., 2015). The most wellknown and researched auxins in plants is indole-3-acetic acid (IAA) because IAA is a crucial physiologically active phytohormone for plants and secondary metabolite of L-tryptophan which have vital role in numerous biological processes as a regulator in plants like; cell expansion, division, differentiation (Lebrazi et al., 2020). Furthermore, it has been reported that plants have more uptake to soil nutrients as bacterial IAA improves both the root surface region and length. Also, most of rhizobacteria can produce IAA. Thus, PGPR strains can change root structure and promote plant development due to their ability to synthesize and secrete plant hormones like IAA, gibberellins (GAs), cytokinins and certain volatiles, hence they are termed phytostimulators (Mohite, 2013; Montana et al., 2014; Vaikuntabu et al., 2014). Especially, potential PGPR strains isolated from the rhizosphere and rhizoplane from different type of agricultural products have performed more potential of IAA production than from the non-rhizospheric soil (Bal et al., 2012).

As it is known, plants are faced to various biotic and abiotic stresses in nature such as cold, drought, flooding, heat, salinity, exposure to heavy metals and lack of nutrients, attack by phytopathogens and pests. Any of these stress conditions are demonstrated to enhancement of ethylene synthesis in plants. Because, ethylene is a precursor of 1- aminocyclopropane-1-carboxylic acid (ACC) so that the ACC deaminase enzyme hydrolyzes as a biosynthetic precursor of the hormone ethylene in plant tissues to ammonia and $\alpha$-ketobutyrate instead of ethylene. The main mechanisms used by PGPR strains to decrease the stress contains reducing the level of ethylene through hydrolyzing ACC by the enzyme ACC deaminase. Therefore, most of PGPR strains have ACC deaminase activity utilized for to decline hazardous effects of ethylene under stressed conditions (Abbas-Zadeh et al., 2010; Qin et al., 2014; Kadıoglu et al., 2016; Misra and Chauhan 2020). 
PGPR strains and their relations with plants are used commercially nowadays and it has huge potential and promise for sustainable agriculture because of their beneficial effects on plenty of agricultural products. It has been studied and examined various type of agricultural crops containing barley, canola, maize, lentils, pepper, cucumber, rice, soy, cowpea, wheat etc. (Adesemoye et al., 2009; Hayat et al., 2010; Sharan and Nehra, 2011).

In this study, we are focused on IAA production and ACC deaminase activity of bacterial strains which were isolated from rhizospheric soil. The main goal of the present study was identified local potential PGPR strains isolated from soil rhizosphere and quantified them in vitro production of IAA and ACC deaminase activity and showed to these potential PGPR strains can be used in as local specific strains in agricultural areas in Ağrı province.

\section{MATERIALS AND METHODS}

\section{Chemicals}

All of the chemicals utilized in the current study were purchased from Merck (Hohenbrunn, Germany), Fluka (Steinheim, Germany), Sigma-Aldrich (St. Louis, USA), Promega (Madison, USA), Oxoid (Hampshire, England), LAB M (Lancashire, England) and Lonza (Rockland, USA).

\section{Collection of Soil Samples and Isolation of Rhizospheric Bacteria}

Rhizospheric bacteria were isolated from soils samples in agricultural lands from Ağr1-Turkey as following procedure in the month of August 2020. Sampling was taken from 3 different sites, at depts of $0-7 \mathrm{~cm}$ in the region of directly surrounding the roots of the wheat, maize and sainfoin plants rhizosphere in agricultural areas. Then, soil samples were transferred under aseptic conditions to Central Research and Application Laboratory, Agri Ibrahim Cecen University. Then serially diluted soil samples $\left(10^{-1}-10^{-7}\right)$ were spread onto Lauria Bertani (LB) agar incubated for 2 days at $28^{\circ} \mathrm{C}$. With the end of incubation period, distinct bacterial colonies were streaked on LB agar plates to obtain pure and single colonies for further studies.

\section{Determination of the Indol Acedic Acid Production}

IAA production is one of the major pivotal natural auxins that promote plant growth. The assay was prepared according to Vaikuntapu et al., (2014) procedure. This procedure was performed as following; bacterial isolates were grown in LB broth medium containing $0.1 \%$ tryptophan and incubated for 72 hours at $28^{\circ} \mathrm{C}$. After the incubation, the isolates were centrifuged at $6000 \mathrm{~g}$ for 30 minutes. Then, $2 \mathrm{ml}$ of the supernatant was taken and mixed with 2 drops of ortho-phosphoric acid and $4 \mathrm{ml}$ of Salkowski solvent $\left(50 \mathrm{ml}\right.$ of $35 \%$ of perchloric acid $+1 \mathrm{ml}$ of $0.5 \mathrm{M} \mathrm{FeCl}_{3}$ solution). Finally, potential IAA production bacterial isolates calorimetric measurement was carried on at $530 \mathrm{~nm}$.

\section{Determination of the ACC Deaminase Enzyme Production}

ACC deaminase enzyme activity was analysed according to the method of Penrose and Glick (2003). In this present protocol, bacterial isolates were inoculated in LB broth medium and incubated at $28{ }^{\circ} \mathrm{C}$ for 24 hours. After an overnight incubation period, $2 \mathrm{ml}$ of each bacterial culture was taken and centrifuged at $8000 \mathrm{~g}$ for 5 minutes. Then, pellets of each sample was washed two times with Dworkin and Foster minimal salts medium. Furthermore, $2 \mathrm{ml}$ of Foster minimal salts medium supplemented with ACC as only nitrogen source (DF-ACC) were transferred to bacterial cultures. The cultures were incubated at $28^{\circ} \mathrm{C}$ for $24 \mathrm{~h}$. Moreover, non-inoculated DF-ACC medium was used as a control group of the experiment and blank sample for the spectrophotometric measurement. Then, cultures were centrifuged at $8000 \mathrm{~g}$ for 5 minutes. $1 \mathrm{ml}$ of each sample were taken from the cultures and centrifuged at $8000 \mathrm{~g}$ for 5 minutes. $100 \mu \mathrm{l}$ of the supernatant was diluted with $1 \mathrm{ml}$ of DF medium. $60 \mu \mathrm{l}$ of each 
working solution was used in the standard ninhydrin experiment $(60 \mu$ l working solution $+120 \mu 1$ ninhydrin solution). The solution was mixed and situated in a boiling water bath for 30 minutes at $65^{\circ} \mathrm{C}$. After boiling, the solution turned into a purple color. The samples were cooled at the room temperature for 20 minutes. When compared to the control, the opaque visibility in color can be evaluated as a positive result. Finally, the calorimetric measurement was performed at $570 \mathrm{~nm}$.

\section{Molecular Identification of Potential IAA and ACC Deaminase Enzyme Production Capability of PGPR strains}

Genomic DNA isolation of the selected potential IAA and ACC deaminase enzyme producer PGPR isolates was used according to method defined by Wilson in 1997. The isolates were identified through 16S rRNA gene sequencing. The partial16S rRNA gene regions were amplified utilizing polymerase chain reaction (PCR) for molecular identification of the bacterial isolates. The primers were 27F (5'-AGAGTTTGATCMTGGCTCAG-3') and 1492R (5'-CGGTTACCTTGTTACGACTT-3'). The reaction mixtures $(30 \mu \mathrm{l})$ reaction included $50 \mathrm{ng}$ of extracted as a template, $1.5 \mathrm{mM} \mathrm{MgCl}_{2}, 0.2$ $\mathrm{mM}$ each dNTP, $1.2 \mu \mathrm{l}$ of dimethyl sulfoxide (DMSO), 25 pmoles of forward primer and reverse primer, and $5 \mathrm{U}$ Taq DNA polymerase along with reaction buffer. The amplification procedure was contained following reactions: The initial step at $95^{\circ} \mathrm{C}$ for $2 \mathrm{~min}$, and 36 cycles of $1 \mathrm{~min}$ at $94{ }^{\circ} \mathrm{C}, 1 \mathrm{~min}$ at $53{ }^{\circ} \mathrm{C}$, 2 min at $72{ }^{\circ} \mathrm{C}$, followed by a final 5 min extension step at $72{ }^{\circ} \mathrm{C}$, then brought down to $4{ }^{\circ} \mathrm{C}$. Amplified 16S rRNA gene PCR products were analysed by QIAxcel ${ }^{\circledR}$ advanced analysis system and sequenced by Macrogen Inc. BLAST Netherlands. The nucleotide BLAST (Basic Local Alignment Search Tool) search program of NCBI was exploited to determine the nucleotide sequence homology and relation to other bacterial sequences existing in the GenBank ${ }^{\circledR}$ (http://blast.ncbi.nlm.nih.gov./blast.cgi). Evolutionary analyses were conducted in MEGA X (Kumar et al., 2018)

\section{RESULTS AND DISCUSSION}

A total of 48 morphologically distinct bacterial isolates were isolated on August from agricultural areas from rhizospheric soil samples from 3 different localities in agricultural lands in Ağr1-Turkey. The rhizospheric bacteria isolated and identified utilizing by $16 \mathrm{~S}$ rRNA gene analysis. Totally, 11 potential bacterial species were shown plant growth promoting activities not only IAA producing but also ACC deaminase avtivities from rhizospheric soil samples. The isolates were on $100 \%$ identical to the closest relatives assigned to GenBank. Determination of nucleotide sequence homology was established via nucleotide BLAST search program of NCBI. The $16 \mathrm{~S}$ rRNA sequences were deposited to GenBank ${ }^{\circledR}$ with provided accession numbers from MW426255 to MW426265 respectively. Detailed information was given in Table 1.

On the basis of 16S rRNA sequences of the isolated strains and the closest relatives from GenBank the neighbour joining phylogenetic tree was constructed (Figure 1). As it's shown in Table 2; 11 isolated species belonging to 3 distinct phyla and 5 order: Proteobacteria (BM2, BM9, BM10, and BM11), Firmicutes (BM1, BM4, BM5, and BM6), Actinobacteria (BM3, BM7, and BM8).

Order I - Bacillales is one the most plenty of order and contains 4 species: Bacillus safensis strain BM-1, Bacillus simplex strain BM-4, Bacillus pumilus strain BM-5, and Bacillus sp. strain BM-6. Junior et al. were reported (2015) production of indole-3-acetic acid by Bacillus isolated from different soils. Cruz-Martín and coauthors were reported (2015) B. pumilus CCIBPC5 grow in culture media without nitrogen, and produced indole acetic acid. Furthermore, B. pumilus enhanced dramatically the height and stem thickness and improves dry and fresh weight of plants. On the other study, Misra and Chauhan (2020) were shown ACC deaminase-producing rhizosphere competent of B. safensis reduce salt stress and promote Zea mays L. growth by modulating ethylene metabolism. Moreover; there are numerous 
studies were reported production of IAA and ACC-deaminase activity as PGP properties of as Bacillus sp. (Rodriquez-Romero et al., 2005; Shim et al., 2014; Gupta and Pandey, 2019).

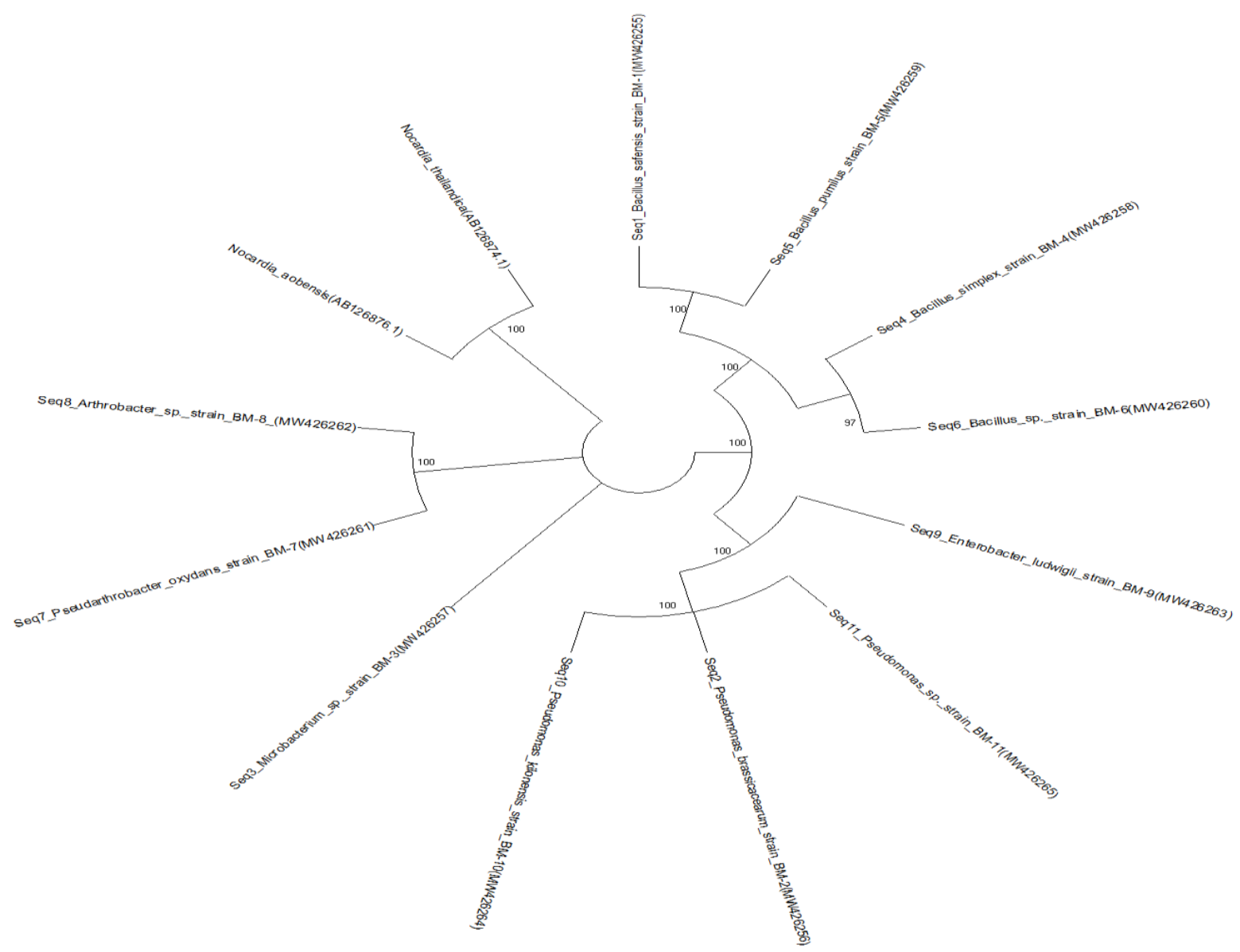

Figure 1. Phylogenetic tree on the basis of 16S rRNA were created using the Neighbor-Joining method (Felsenstein, 1985; Saitou and Nei 1987; Tamura et al., 2004). Evolutionary analyses were carried on MEGA X (Kumar et al., 2018).

Order II-Pseudomonadales is second major order of the current study and it is including 3 various species; Pseudomonas brassicacearum strain BM-2, Pseudomonas kilonensis strain BM-10, and Pseudomonas sp. strain BM-11. According to the literature, it is also reported more studies about their PGP. Therefore, Pseudomonas sp. is known one of the common genus of PGPR strains which are isolated from rhizospheric soil samples. For instance; Qin et al. (2014) were found activity of ACC deaminase and IAA producing bacteria by $16 \mathrm{~S}$ rRNA gene sequence $P$. brassicacearum subsp. brassicacearum from coastal halophytic medicinal plant. Moreover, Pseudomonas species are known not only IAA production and ACC- deaminase activity, but also other PGP properties such as; nitrogen fixation, phosphate solubilization and siderophore production and Pseudomonas species have been reported intensively utilized in agricultural applications according to the literature (Gu et al., 2020).

Order III- Actinomycetales contains 2 species: Microbacterium sp. strain BM-3 and Arthrobacter sp. strain BM-8. A study by Samayoa et al. (2020) were isolated and screened of PGP properties of numerous distinct type of bacterial species from soil rhizosphere and root endophyte of onion. Microbacterium hydrocarbonoxydans and Microbacterium laevaniforman have shown almost all PGPR 
properties including IAA production and ACC deaminase activity and also Microbacterium sp. was shown IAA production according to their study.

Order IV- Micrococcales presented by single species Pseudarthrobacter oxydans strain BM-7. Mesa-Marín with coauthors (2019) were reported effect of PGPR on Salicornia ramosissima seed germination under salinity and Pseudarthrobacter oxydans SRT15 was showed PGP properties such as; nitrogen-fixation, phosphate solubilization and IAA production.

Order V-Enterobacterales also presented by one species Enterobacter ludwigii strain BM-9. Singh (2015) studied some of the PGP properties of Enterobacter ludwigii PGP 19 isolated from soil rhizosphere of Pennisetum glacum (pearl millet). The strain E. ludwigii PGP 19 was able to active phosphate solubilization, IAA production, and ACC deaminase activity. According to a report by Aarab et al. (2015) E. ludwigii isolated rhizospheric soils of rice demonstrated IAA production.

Table 1. Taxonomic affiliation of the bacterial isolates and their GenBank ${ }^{\circledR}$ accession numbers

\begin{tabular}{llcc}
\hline Strain Code & Strain Name & Accession number & Percentage identity \\
\hline BM1 & Bacillus safensis & MW426255 & 100 \\
BM2 & Pseudomonas brassicacearum & MW426256 & 100 \\
BM3 & Microbacterium sp. & MW426257 & 100 \\
BM4 & Bacillus simplex & MW426258 & 100 \\
BM5 & Bacillus pumilus & MW426259 & 100 \\
BM6 & Bacillus sp. & MW426260 & 100 \\
BM7 & Pseudarthrobacter oxydans & MW426261 & 100 \\
BM8 & Arthrobacter sp. & MW426262 & 100 \\
BM9 & Enterobacter ludwigii & MW426263 & 100 \\
BM10 & Pseudomonas kilonensis & MW426264 & 100 \\
BM11 & Pseudomonas sp. & MW426265 & 100 \\
\hline
\end{tabular}

Table 2. Detailed information of IAA production and ACC deaminase activity of potential PGPR strains (+: slight positive, ++ : moderately positive, +++ : strong positive)

\begin{tabular}{lcccc}
\hline Species Name & $\begin{array}{c}\text { IAA } \\
\text { Production }\end{array}$ & $\begin{array}{c}\text { ACC } \\
\text { Deaminase Production }\end{array}$ & Order & Phylum \\
\hline Bacillus safensis BM-1 & +++ & +++ & Bacillales & Firmicutes \\
Pseudomonas brassicacearum BM2 & +++ & +++ & Pseudomonadales & Proteobacteria \\
Microbacterium sp. BM-3 & +++ & +++ & Actinomycetales & Actinobacteria \\
Bacillus simplex BM-4 & +++ & + & Bacillales & Firmicutes \\
Bacillus pumilus BM-5 & +++ & +++ & Bacillales & Firmicutes \\
Bacillus sp. BM-6 & +++ & +++ & Bacillales & Firmicutes \\
Pseudarthrobacter oxydans BM-7 & +++ & +++ & Micrococcales & Actinobacteria \\
Arthrobacter sp. BM-8 & +++ & ++ & Actinomycetales & Actinobacteria \\
Enterobacter ludwigii BM-9 & +++ & +++ & Enterobacterales & Proteobacteria \\
Pseudomonas kilonensis BM-10 & +++ & + & Pseudomonadales & Proteobacteria \\
Pseudomonas sp. BM-11 & +++ & + & Pseudomonadales & Proteobacteria \\
\hline
\end{tabular}

It was also shown by previous studies; rhizospheric bacteria from soil samples have capability to fix atmospheric nitrogen, phosphate solubilization, synthesing siderophores, ACC deaminase activity and type of phytohormones such as auxins for provide it to plants as a plant growth property (Alaylar et al., 2018; Ferchichi et al., 2019). IAA production is one of the most effective PGP mechanism (Pawlik et al., 2017). It is promoting to plant growth directly by enhancing length and root surfaces by stimulating 
plant cell elongation for providing to soil nutrient from plants (Phetcharat and Duangpaeng 2012; Vinayarani and Prakash 2018). There are many reports have been shown IAA production by rhizospheric and endophytic bacteria (Ray et al., 2016; Chowdhury et al., 2017; Vinayarani and Prakash 2018; Wozniak et al., 2019). Various rhizospheric bacteria have potential to produce the auxin phytohormone IAA, these kind of rhizospheric microorganisms produce auxins in the presence of a favourable precursor like L-tryptophane (Phetcharat and Duangpaeng 2012). On the other hand, most of the plant growth promoting rhizospheric strains are well-known with ACC deaminase activity which have role in decrease to level of ethylene stress and help their host plants deal with numerous stress factors like abiotic and biotic factors.

In the line with this purpose, we observed IAA production and ACC deaminase activity as PGP by rhizospheric soil samples in agricultural areas from Ağr1-Turkey. When the compare with our results with 25 of 48 strains were demonstrated IAA production. 11 of 48 the best IAA production potential stains were chosen. On the other hand, 11 of 48 the rhizospheric bacteria were shown ACC deaminase activity.

In summary, as it mentioned it; PGPR have been revealed to beneficial effects of plant development and health. For sustainable agricultural applications, microorganism based fertilizers can be used instead of chemical fertilizers because of their eco-friendly low cost usage. Moreover, potential local PGPR strains can be more effective usage on agricultural products. Therefore, the results showed that, plant growth promoting property IAA production and ACC deaminase activity from rhizospheric bacteria with the selected from soil rhizosphere. According to our knowledge, the present study reveals for the first time to the isolation and identification of rhizospheric bacteria from soil samples in Ağr1 province which have IAA production and ACC deaminase activity. It can be use in agricultural application for further.

\section{CONCLUSION}

It can be concluded that soil rhizosphere as the huge potential source for obtaining new bacterial strains and their metabolites. In this regards; It can be understood from the present study that rhizospheric bacteria isolated from agricultural areas have crucial PGP such as IAA production and ACC deaminase activity. It is important to note that unknown rhizospheric bacteria community in soil rhizosphere in agricultural areas can be vital role in agricultural products. Rhizospheric bacteria deal with agricultural products such as wheat, barley, canola, oat, cucumber etc. have unique strategies that enhance growth and yield productivity of agricultural products. Taking into consideration of its economic value and vital roles of PGPR strains in plant health, enhance productivity, growth, such knowledge gap needs to be filled for active utilization of PGPR strains and detection of novel PGPR strains from local strains in agricultural areas.

\section{Conflict of Interest}

The article authors declare that there is no conflict of interest between them.

\section{Author's Contiibutions}

The authors declare that they have contributed equally to the article.

\section{REFERENCES}

Abbas-Zadeh P, Saleh-Rastin N, Asadi-Rahmani H, Khavazi K, Soltani A, Shoary-Nejati R, Miransari M 2010. Plant Growth-Promoting Activities of Fluorescent pseudomonads, Isolated from the Iranian soils. Acta physiologiae plantarum, 32, 281-288. 
Aarab S, Ollero FJ, Megias M, Laglaoui A, Bakkali M, Arakrak A, 2015. Isolation and Screening of Bacteria from Rhizospheric Soils of Rice Fields in Northwestern Morocco for Different Plant Growth Promotion (PGP) Activities: An in Vitro Study. International Journal of Current Microbiology and Applied Sciences, 4, 260-269.

Adesemoye AO, Torbert HA, Kloepper JW, 2009. Plant Growth-Promoting Rhizobacteria Allow Reduced Application Rates of Chemical Fertilizers. Plant Microbe Interactions, 58, 921-929.

Afzal I, Iqrar I, Shinwari ZK, Yasmin A, 2017. Plant Growth-Promoting Potential of Endophytic Bacteria Isolated from Roots of Wild Dodonaea viscosa L. Plant Growth Regulation, 8, 399-408.

Ahmad F, Ahmad I, Khan MS, 2008. Screening of Free-Living Rhizospheric Bacteria for Their Multiple Plant Growth Promoting Activities. Microbiological Research, 163, 173-181.

Alaylar B, Güllüce M, Karadayı G, Karadayı M (2018) Isolation of PGPR Strains with Phosphate Solubilizing Activity from Erzurum and Their Molecular Evaluation by Using Newly Designed Specific Primer for $p q q B$ gene. International Journal of Scientific \& Engineering Research, 9, 103106.

Alaylar B, Gulluce M, Karadayi M, Isaoglu M, 2019. Rapid Detection of Phosphate Solubilizing Bacteria from Agricultural Areas in Erzurum. Current Microbiology, 76, 804-809.

Alaylar B, Gulluce M, Karadayi M, 2020a. Detection of the NifH Gene in Nitrogen Fixing Bacteria from Agricultural Areas in Erzurum. Fresenius Environmental Bulletin, 29, 809-814.

Alaylar B, Egamberdieva D, Gulluce M, Karadayi M, Arora NK, 2020b. Integration of Molecular Tools in Microbial Phosphate Solubilization Research in Agriculture Perspective. World Journal of Microbiology and Biotechnology, 36, 1-12.

Bal HB, Das S, Dangar TK, Adhya TK, 2012. ACC Deaminase and IAA Producing Growth Promoting Bacteria from the Rhizosphere Soil of Tropical Rice Plant. Journal of Basic Microbiology, 53, 972984.

Beneduzi A, Ambrosini A, Passaglia LMP, 2012. Plant Growth-Promoting Rhizobacteria (PGPR): Their Potential as Antagonists and Biocontrol Agents. Genetics and Molecular Biology, 35, 1044-1051.

Chowdhury EK, Jeon J, Rim SK, Park YH, Lee SK, Bae H, 2017. Composition, Diversity and Bioactivity of Culturable Bacterial Endophytes in Mountain-Cultivated Ginseng in Korea. Scientific Reports. 7, 110.

Cruz-Martin M, Mena E, Sanchez-Garcia C, Roque B, Acosta-Suarez M, Pichardo T, Leiva-Mora M, Alvarado-Capo Y, 2015. The Effects of Plant Growth Promoting Bacillus pumilus CCIBPC5 on 'Grande Naine' (Musa AAA) Plants in Acclimatization Stage. Biotecnología Vegetal, 15, 151-156.

Duca D, Lorv J, Patten CL, Rose D, Glick BR, (2014). Indole-3-Acetic Acid in Plant-Microbe Interactions. Antonie van Leeuwenhoek, 106, 85-125.

Egamberdieva D, 2015. Plant-Growth-Promoting Rhizobacteria Isolated from Calcisol in a Semi-Arid Region of Uzbekistan: Biochemical Characterization and Effectiveness. Journal of Plant Nutrition and Soil Science, 168, 94-99.

Felsenstein J, 1985. Confidence Limits on Phylogenies: An Approach Using the Bootstrap. Evolution, 39, 783-791.

Ferreira CMH, Soares HMVM, Soares EV, 2019. Promising Bacterial Genera for Agricultural Practices: An Insight on Plant Growth-Promoting Properties and Microbial Safety Aspects. Science of the Total Environment, 682, 779-799.

Ferchichi N, Toukabri W, Boularess M, Smaoui A, Mhamdi R and Trabelsi D, 2019. Isolation, Identification and Plant Growth Promotion Ability of Endophytic Bacteria Associated with Lupine Root Nodule Grown in Tunisian Soil. Archives of Microbiology, 201, 1333-1349.

Gu Y, Wang J, Zhenyuan X, Wei HL, 2020. Characterization of a Versatile Plant Growth-Promoting Rhizobacterium Pseudomonas mediterranea Strain S58. Microorganism, 8,1-15. 
Gupta S, Pandey S, 2019. ACC Deaminase Producing Bacteria with Multifarious Plant Growth Promoting Traits Alleviates Salinity Stress in French Bean (Phaseolus vulgaris) Plants. Frontiers in Microbiology, $10,1-17$.

Hayat R, Ali S, Amara U, Khalid R, Ahmed I, 2010. Soil Beneficial Bacteria and Their Role in Plant Growth Promotion: A Review. Annals of Microbiology, 60, 579-598.

Junior AFC, De Oliveira AG, De Oliveira LA, Dos Santos GR, Chagas LFB, Da Silva ALL, Costa J, 2015.

Production of Indole-3-Acetic Acid by Bacillus Isolated from Different Soils. Bulgarian Journal of Agricultural Science, 21, 282-287.

Kadioglu G, Koseoglu M, Ozdal M, Sezen A, Ozdal O, Algur OF, 2016. Isolation of Cold Tolerant and ACC Deaminase Producing Plant Growth Promoting Rhizobacteria from High Altitudes. Romanian Biotechnological Letters, 23, 13479-13486.

Kloepper JW, Schroth MN, 1978. Plant Growth Promoting Rhizobacteria on Radish. In: Proceedings of The 4th International Conference on Plant Pathogenic Bacteria, Angers, France, 2017, pp: 879-882.

Kumar S, Stecher G, Li M, Knyaz C, Tamura K, 2018. MEGA X: Molecular Evolutionary Genetics Analysis Across Computing Platforms. Molecular Biology and Evolution, 35, 1547-1549.

Lebrazi S, Fadil M, Chraibi M, Fikri-Benbrahim K, 2020. Screening and Optimization of Indole-3-Acetic Acid Production by Rhizobium sp. Strain Using Response Surface Methodology. Journal of Genetic Engineering and Biotechnology, 18, 1-10.

Mesa-Marin J, Perez-Romero J, Mateos-Naranjo E, Bernabeu-Meana M, Pajuelo E, Rodriquez-Llorente ID, Redondo-Gomez S, 2019. Effect of Plant Growth-Promoting Rhizobacteria on Salicornia ramosissima Seed Germination under Salinity, $\mathrm{CO}_{2}$ and Temperature Stress. Agronomy, 9, 1-14.

Misra S, Chauhan PS, 2020. ACC Deaminase Producing Rhizosphere Competent Bacillus spp. Mitigate Salt Stress and Promote Zea mays Growth by Modulating Ethylene Metabolism. 3 Biotech, 10, 1-14.

Mohite B, 2013. Isolation and Characterization of Indole Acetic Acid (IAA) Producing Bacteria from Rhizospheric Soil and Its Effect on Plant Growth. Journal of Soil Science and Plant Nutrition, 13, 638649.

Montano FP, Alias - Villegas C, Bellogin RA, Cerro P, Espunsy MR, Jimenez-Guerrero I, Baena L, Ollero FJ, Cubo T, 2014. Plant Growth Promotion in Cereal and Leguminous Agricultural Important Plants: From Microorganism Capacities to Crop Production. Microbiological Research, 169, 325-336.

Pawlik M, Cania B, Thijs S, Vangronsveld J, Piotrowska Seget Z, 2017. Hydrocarbon Degradation Potential and Plant Growth Promoting Activity of Culturable Endophytic Bacteria of Lotus corniculatus and Oenothera biennis from a Long-Term Polluted Site. Environmental Science and Pollution Research, 24, 19640-19652.

Penrose DM, Glick BR, 2003. Methods for Isolating and Characterizing ACC Deaminase-Containing Plant Growth-Promoting Rhizobacteria. Physiologia Plantarum, 118, 10-15.

Phetcharat P, Duangpaeng A, 2012. Screening of Endophytic Bacteria from Organic Rice Tissue for Indole Acetic Acid Production. Procedia Engineering, 32, 77-183.

Ray S, Singh S, Sarma BK, and Singh HB, 2016. Endophytic Alcaligenes Isolated from Horticultural and Medicinal Crops Promotes Growth in Okra (Abelmoschus esculentus). Journal of Plant Growth Regulation, 35, 401-412.

Rodríguez-Romero AS, Guerra MS, Jaizme-Vega MD, 2005i Effect of Arbuscular Mycorrhizal Fungi and Rhizobacteria On Banana Growth and Nutrition. Agronomy for Sustainable Development, 25, 395399.

Saitou N, Nei M, 1987. The Neighbor-Joining Method: A New Method for Reconstructing Phylogenetic Trees. Molecular Biology and Evolution, 4, 406-425.

Samayoa BE, Shen FT, Lai WA, Chen WC, 2020. Screening and Assessment of Potential Plant Growthpromoting Bacteria Associated with Allium cepa Linn. Microbes and Environment, 35, 1-10. 
Sharan BS, Nehra V, 2011. Plant Growth Promoting Rhizobacteria: A Critical Review. Life Sciences and Medicine Research, 2011, 1-30.

Shim J, Kim JW, Shea P, Oh BT, 2014. IAA production by Bacillus sp. JH 2-2 Promotes Indian Mustard Growth in the Presence of Hexavalent Chromium. Journal of Basic Microbiology, 55, 652-658.

Sing BP, 2015. Isolation and Characterization of Multifarious Plant Growth Promoting Bacteria Enterobacter ludwigii PGP 19 Isolated from Pearl Millet. International Journal of Science and Research, 1, 262265.

Qin S, Zhang YJ, Yuan B, Xu PY, Xing K, Wang J, Jiang JH, 2014. Isolation of ACC Deaminase-Producing Habitat-Adapted Symbiotic Bacteria Associated with Halophyte Limonium sinense (Girard) Kuntze and Evaluating Their Plant Growth-Promoting Activity under Salt Stress. Plant Soil, 374, 753-766.

Tamura K, Nei M, Kumar S, 2004. Prospects for Inferring Very Large Phylogenies by Using the NeighborJoining Method. Proceedings of the National Academy of Sciences, USA, 101, 11030-11035.

Vaikuntapu PR, Dutta S, Samudrala RB, Rao VRVN, Kalam S, Podile AR, 2014. Preferential Promotion of Lycopersicon esculentum (Tomato) Growth by Plant Growth Promoting Bacteria Associated with Tomato. Indian Journal of Microbiology, 54, 403-412.

Vinayarani G, Prakash HS, 2018. Growth Promoting Rhizospheric and Endophytic Bacteria from Curcuma Longa L. as Biocontrol Agents Against Rhizome Rot and Leaf Blight Diseases. Plant Pathology Journal, 34, 218-235.

Wilson K, 1997. Preparation of Genomic DNA from Bacteria. In: Ausubel FM, Brent R, Kingston RE, Moore DD, Seidman JG, Smit JA, Struhl K, (eds) Current Protocols in Molecular Biology. (Volume 1). Wiley Interscience, pp. 241-245, Brooklyn, New York-USA.

Wozniak M, Gałazka A, Tyskiewicz R, Sciseł JJ, 2019. Endophytic Bacteria Potentially Promote Plant Growth by Synthesizing Different Metabolites and Their Phenotypic/Physiological Profiles in the Biolog GEN III MicroPlateTM Test. International Journal of Molecular Sciences, 20, 1-24. 